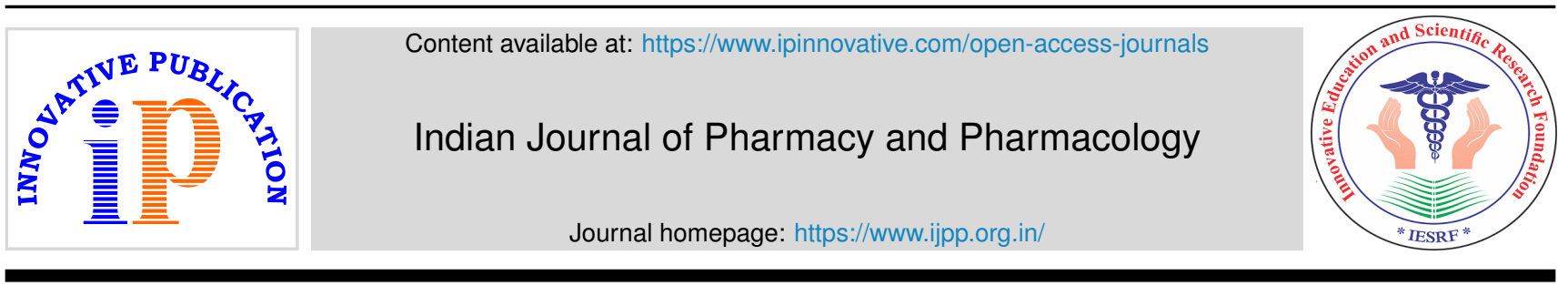

\title{
Editorial
}

\section{Mucormycosis and its implication in COVID-19}

\author{
Aseem Setia ${ }^{1}$, Sankha Bhattacharya ${ }^{\circledR 2, *}$ \\ ${ }^{1}$ Dept. of Pharmaceutics, ISF College of Pharmacy, Moga, Punjab, India \\ ${ }^{2}$ Dept. of Pharmaceutics, School of Pharmacy \& Technology Management, SVKM'S NMIMS Deemed-to be University, Shirpur, \\ Maharashtra, India
}

\section{A R T I C L E I N F O}

Article history:

Received 19-05-2021

Accepted 21-05-2021

Available online 17-06-2021

Keywords:

Mucormycosis

Amphotericin B

Diabetic acidosis

COVID- 19

\begin{abstract}
A B S T R A C T
Mucormycosis is a life-threatening fungal infection caused by a group of moulds known as mucormycetes. It is a viral disease, increasingly progressive, rapidly triggers in diabetic, immunocompromised and trauma patients. Diabetic patients seem to have the classic rhinocerebral variant. Rhinocerebral mucormycosis begins as a nasal cavity, paranasal sinus, and orbital soft tissue infection. In immunocompetent patients, direct injection also induces cutaneous form. Cutaneous mucormycosis occurs in soft tissue and may infect underlying tissues. Mucormycosis is more frequent in people with major underlying disorders such as diabetic acidosis or acute leukaemia and those taking corticosteroids or cytotoxic drugs. This disease occurs in patients by inhaling fungus spores. Mucormycosis occurs in clinical manifestations. Disseminated mucormycosis is a rare form of mucormycosis, affecting individuals with compromised immune systems. The disease travels to other areas of the body, thereby being prevalent. Brain, core, spleen, eyes, and other organs are among the organs that may be affected. Mucormycosis is a dangerous infection that requires antifungal drugs such as amphotericin B, posaconazole, or isavuconazole. This compilation addresses conceptual background on medicines used to treat mucormycosis, especially in India.
\end{abstract}

(C) This is an open access article distributed under the terms of the Creative Commons Attribution License (https://creativecommons.org/licenses/by/4.0/) which permits unrestricted use, distribution, and reproduction in any medium, provided the original author and source are credited.

\section{Introduction}

Mucormycosis is an extremely rare disease. ${ }^{1}$ Major cause of mucor mold includes dirt trees, compost, rotting vegetables, and fruits. ${ }^{2}$ Mucormycosis is triggered by a family of moulds in the order Mucorales. Rhizopus spp., Mucor spp., and Lichtheimia spp. (formerly of the genera Absidia and Mycocladus) are the most commonly found organisms in mucormycosis, followed by Rhizomucor spp., Cunninghamella spp., Apophysomyces spp., and Saksenaea spp. ${ }^{3}$ It is common and can be detected in dirt, air, and even in noses and mucus. It influences the sinuses, the brain, and the lungs, although it can be fatal for diabetic patients or individuals who are seriously immunocompromised, such as cancer victims or people with HIV/AIDS. ${ }^{4}$ Mucormycosis is a disease that has been identified throughout the world. ${ }^{5}$

\footnotetext{
* Corresponding author

E-mail address: sankhabhatt@gmail.com (S. Bhattacharya).
}

This virus has the ability to affect people of all ages, particularly premature babies. Such typical signs involve tissue loss (necrosis) of the roof of the mouth (palate), disintegration of the thin cartilage and bone (septum) wall that separates the nostrils (septum), swelling of the site all around nose (perinasal area), and redness (erythema) of the skin overlying the sinus and the eye socket (orbit). ${ }^{6}$ Owing to a loss of oxygen, there may be bluish discoloration of the skin near the sinuses or the eye socket (cyanosis). Blurred or double vision may occur at times. Serious tissue loss (necrosis) may arise if the infection goes undetected, and the infection may severely affect facial structures. Many individuals who have recovered from COVID-19 have recently been diagnosed with black fungus or mucormycosis disease. ${ }^{7}$ The infection infiltrates the sinuses and spreads to the intraorbital and intracranial areas. If the disease progresses unchecked, 50-80 percent of patients will die. ${ }^{8} \mathrm{~A}$ high likelihood of mucormycosis 
was found in a COVID-19 patient with unregulated diabetes and diabetic ketoacidosis, patients that have administered large doses of intravenous or oral steroids for extended periods of time, as well as patients who have undergone immunomodulators (drugs used in disorders such as cancer to alter the immune system's response), are more susceptible to black fungus. ${ }^{9}$ Clinically, rhinocerebral mucormycosis can manifest with atypical signs and symptoms resembling complicated sinusitis, such as nasal blockage, crusting, proptosis, and fever. ${ }^{10}$ In most cases, rhino-orbital-cerebral infection begins in the paranasal sinuses, causing bone loss and eventual penetration of the orbit, eye, and brain. ${ }^{11}$ Fever, cough, chest pain, blood in sputum after coughing, and deteriorating respiratory problems are all symptoms of pulmonary mucormycosis (involving the chest). ${ }^{12}$ The most prevalent types of mucormycosis in immunocompetent patients are cutaneous and soft-tissue mucormycosis. ${ }^{13}$ Cutaneous and soft-tissue mucormycosis are the most prevalent types of mucormycosis in immunocompetent patients, ${ }^{14}$ occurring mainly as a result of skin damage caused by serious injury (e.g., natural disasters, motor vehicle collisions, improvised explosive devices in theatres of war, or iatrogenic sources), surgery, or burns. Moreover, Covid-19 is a potentially fatal infectious disease, infected patients have an increase in inflammatory cytokines and reduced cell-mediated immunity, with lower CD4+ T and $\mathrm{CD} 8+\mathrm{T}$ cells counts, ${ }^{15}$ suggesting vulnerability to fungal co-infections. Patients who were seriously ill, including those confined to intensive care units and those who needed mechanical ventilation, or who had prolonged hospital stays, including up to 50 days, were more likely to develop fungal co-infections. ${ }^{16}$ Excessive use of steroids in the treatment of Covid-19 can also inhibit immunity, causing opportunistic fungal infections to colonise. ${ }^{17}$ The detection of distinctive signs, a comprehensive case history, a rigorous clinical assessment, and a number of advanced examinations are used to make a diagnosis of mucormycosis. ${ }^{18}$ Mucormycosis is difficult to diagnose and the symptoms are shared among a variety of diseases, including several forms of infection. ${ }^{19}$ Mold in infected tissue is used to make a diagnosis, which is often confirmed by a test called a fungal culture. ${ }^{20} \mathrm{~A}$ timely diagnosis is critical so that recovery can continue as soon as possible. Mucormycosis is a dangerous infection that requires antifungal medication, typically amphotericin $\mathrm{B}$, posaconazole, or isavuconazole. ${ }^{21}$ These medications are administered either intravenously (amphotericin B, posaconazole, isavuconazole) or orally (amphotericin B, posaconazole, isavuconazole). ${ }^{22}$ Other medications, such as fluconazole, voriconazole, and echinocandins, do not work against the fungi that cause mucormycosis. ${ }^{23}$ Mucormycosis frequently necessitates surgery to remove the infected tissue. ${ }^{24}$ Polyenes (amphotericin formulations) and triazoles are the two major types of antifungal drugs used to treat mucormycosis (isavuconazole and posaconazole). ${ }^{25}$ The two agents currently approved by the FDA for the primary treatment of mucormycosis are amphotericin B and isavuconazole. ${ }^{26}$ Posaconazole can be used off-label for salvage treatment in patients intolerant to amphotericin B. ${ }^{27}$ It has also been used as stepdown therapy after initial control of the disease with amphotericin. Liposomal amphotericin B at a dosage of $5-10 \mathrm{mg} / \mathrm{kg}$ per day is currently recommended for the treatment of mucormycosis. ${ }^{28}$ In the absence of intervention of the central nervous system, a dosage of $5 \mathrm{mg} / \mathrm{kg}$ is recommended. Liposomal amphotericin at $3 \mathrm{mg} / \mathrm{kg} / \mathrm{day}$ was similarly successful but safer and better tolerated than $10 \mathrm{mg} / \mathrm{kg} /$ day in a randomised controlled study of 201 patients with invasive mould disease. ${ }^{29}$ In conclusion, doctors caring for seriously ill COVID-19 patients must be mindful of dangerous diseases that can hinder COVID-19 care. To improve results in mucormycosis, early diagnosis and timely management are needed. ${ }^{30}$

\section{Conclusion}

Novel coronavirus affects many life worldwide. A second wave of virus rapidly spreading known as black fungus (mucormycosis). Many individuals who have recovered from COVID-19 have recently been diagnosed with black fungus or mucormycosis disease. Mucormycosis is difficult to diagnose and the symptoms are shared among a variety of diseases, including several forms of infection. Mold in infected tissue is used to make a diagnosis, which is often confirmed by a test called a fungal culture. As such no proper vaccine or medication is available for black fungus. The two agents currently approved by the FDA for the primary treatment of mucormycosis are amphotericin B and isavuconazole.

\section{Conflict of Interest}

None.

\section{References}

1. Razem B, Dennai Y, Slimani F. Chronical rhino-orbital mucormycosis in an immunocompetent host: A case report. Int J Surg Case Rep. 2021;82:105882. do1:10.1016/].1]Scr.2021.105882

2. Delgado-Ospina J, Molina-Hernández JB, Chaves-López C, Romanazzi G, Paparella A. The Role of Fungi in the Cocoa Production Chain and the Challenge of Climate Change. J Fungi. 2021;7(3):202. do1:10.3390/jof7030202

3. Nagy G, Kiss S, Varghese R, Bauer K, Szebenyi C. Characterization of Three Pleiotropic Drug Resistance Transporter Genes and Their Participation in the Azole Resistance of Mucor circinelloides. Front Cell Infect Microbiol. 2021;11:660347. 101:10.3380/4cimb.2021660347.

4. Salian VS, Wright JA, Vedell PT, Nair S, Li C. COVID-19 Transmission, Current Treatment, and Future Therapeutic Strategies. Mol Pharm. 2021;18(3):754-71.

5. Patil S, Sarate D, Chopade S, Khade M, Dhage S, Kangate S. Emerging Challenge of Mucormycosis in post COVID Patients. IAR J Med Case Rep. 2021;2(3):7-10. do1:10.47310/1ar]mcr.2021.v02103.002 
6. Ogle OE. Advanced Intraoral Surgery, An Issue of Oral and Maxillofacial Surgery Clinics of North America. vol. Vol. 33. Elsevier Health Sciences; 2021.

7. Sharma S, Grover M, Bhargava S, Samdani S, Kataria T. Post coronavirus disease mucormycosis: a deadly addition to the pandemic spectrum. J Laryngol Otol. 2021;135(5):442-7.

8. Bilyk JR, Murchison AP. Ocular Adnexal Lymphoproliferative Disease. In: Smith and Nesi's Ophthalmic Plastic and Reconstructive Surgery; 2021. p. 769-816.

9. Werthman-Ehrenreich A. Mucormycosis with orbital compartment syndrome in a patient with COVID-19. Am J Emerg Med. 2021;42:264.e5. doi:10.1016/1.ajem.2020.09.032

10. Tong CM, Kurji K. Blepharitis: Overview and Classification. In: Cornea, E-Book; 2021. p. 308.

11. Gupta S. Orbital inflammation. In: Smith and Nesi's Ophthalmic Plastic and Reconstructive Surgery. Springer; 2021. p. 743-68.

12. Singhal T. The Chronic Effects of COVID-19 or "Long COVID. Indian Practit. 2021;74(4):24-31.

13. Coerdt KM, Zolper EG, Starr AG, Fan KL, Attinger CE, Evans KK. Cutaneous mucormycosis of the lower extremity leading amputation in two diabetic patients. Arch Plast Surg. 2021;48:2316. ब01:10.59प9/aps.2020.00549.

14. Amanati A, Barzegar H, Pouladfar G, Dashti AS, Abtahi M, Khademi $\mathrm{B}$, et al. Orbital mucormycosis in immunocompetent children; review of risk factors, diagnosis, and treatment approach. BMC Infect Dis. 2020;20(1):1-9.

15. Bo X, Fan CY, Wang AL, Zou YL, Yu YH, He C. Suppressed $\mathrm{T}$ cell-mediated immunity in patients with COVID-19: a clinical retrospective study in Wuhan, China. J Infect. 2020;81(1):51-60.

16. Zhang G, Hu C, Luo L, Fang F, Chen Y, Li J, et al. Clinical features and outcomes of 221 patients with COVID-19 in Wuhan, China. $J$ Clin Virol. 2020;127:104364. [oi:10.1016/j.jcv.2020.104364.

17. Favalli EG, Ingegnoli F, Lucia O, Cincinelli G, Cimaz R, Caporali R. COVID-19 infection and rheumatoid arthritis: Faraway, so close! . Autoimm rRv. 2020;19(5):102523.

18. Pappas PG, Boulware DR, Kontoyiannis DP, Miceli MH, OstroskyZeichner L, Spec A, et al. Clinical mycology today: A synopsis of the mycoses study group education and research consortium (MSGERC) second biennial meeting. Med Mycol. 2020;58(5):569-8.

19. Chegini Z, Didehdar M, Khoshbayan A, Rajaeih S, Salehi M, Shariati A. Epidemiology, clinical features, diagnosis and treatment of cerebral mucormycosis in diabetic patients: A systematic review of case reports and case series. Mycoses. 2020;63(12):1264-82.

20. Hoenigl M, Salmanton-García J, Walsh TJ, Nucci M, Neoh CF, Jenks JD, et al. Global guideline for the diagnosis and management of rare mould infections: an initiative of the European Confederation of Medical Mycology in cooperation with the International Society for Human and Animal Mycology and the. Lancet Infect Dis. 2021 ;01:10.1016/S1473-3099(20)30784-2
21. Miller R, Farrugia L, Leask J, Khalsa K, Khanna N, Melia L. Successful treatment of Rhizopus arrhizus rhino-orbitalcerebral mucormycosis with isavuconazole salvage therapy following extensive debridement. Med Mycol Case Rep. 2021;32:39-42. doi:0.1016/1.mmcr.2021.03.005

22. Sinha S, Sehgal A, Sehgal R. Association of ACE2 receptor and ACEIs/ARBs with disease severity in COVID-19. Drug Discov Ther. 2020;14:161-70. 101:-105582/dat.202003064

23. Livengood SJ, Drew RH, Perfect JR. Combination Therapy for Invasive Fungal Infections. Curr Fungal Infect Rep. 2020;14:40-9.

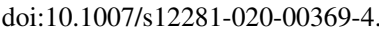

24. Jeyaraj P. Sino-Maxillary Mucormycosis of Iatrogenic Etiology in an Immunocompetent Patient-Importance of Early Diagnosis and Prompt Management. 2021;2(1):1-8.

25. Gómez-López A. Antifungal therapeutic drug monitoring: focus on drugs without a clear recommendation. Clin Microbiol Infect. 2020;26(11):1481-7. doi:10.1016/j.cmi.2020.05.037.

26. Gebremariam T, Alkhazraji S, Alqarihi A, Wiederhold NP, Shaw $\mathrm{KJ}$, Patterson T, et al. Fosmanogepix (APX001) is effective in the treatment of pulmonary murine mucormycosis due to Rhizopus arrhizus. Antimicrob Agents Chemother. 2020;64(6):e00178-20.

27. Liang Y, Chen X, Wang J, Guo C, Liu F, Yang J. Oral posaconazole and bronchoscopy as a treatment for pulmonary mucormycosis in pediatric acute lymphoblastic leukemia patient: A case report. Medicine (Baltimore). 2021;100(6)::e24630.

28. Jestin M, Azoulay E, Pène F, Bruneel F, Mayaux J, Murgier M, et al. Poor outcome associated with mucormycosis in critically ill hematological patients: results of a multicenter study. Ann Intensive

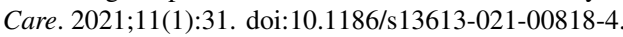

29. Faustino C, Pinheiro L. Lipid Systems for the Delivery of Amphotericin B in Antifungal Therapy. Pharmaceutics. 2020;12(1):29. doi:10.3390/pharmaceutics 12010029.

30. Garg D, Muthu V, Sehgal I, Ramachandran R, Kaur H, Bhalla A, et al. Coronavirus disease (Covid-19) associated mucormycosis (CAM): case report and systematic review of literature. Mycopathologia. 2021;186(2):289-98

\section{Author biography}

Aseem Setia, PG Student

Sankha Bhattacharya, Associate Professor (1) https://orcid.org/0000 0002-0771-9582

Cite this article: Setia A, Bhattacharya S. Mucormycosis and its implication in COVID-19. Indian J Pharm Pharmacol 2021;8(2):97-99. 